\title{
Bruxas Modernas: um estudo sobre identidade feminina entre praticantes de wicca
}

AndréaOsório O objetivo deste artigo é apresentar a importância das diferenças de gênero no IFCS/UFRJ pensamento e prática wiccanas, o que permitiu observar a construção de uma forma de identidade feminina contemporânea: a das bruxas modernas. Durante pesquisa realizada entre 1999 e 2000, na região do Rio de Janeiro, acompanhei rituais religiosos, observei encontros e reuniões, entrevistei alguns praticantes e participei de três listas de discussão na Internet. A partir do material coletado, pude desenvolver uma análise sobre o tipo de identidade feminina construída dentro do pensamento e da prática wiccanas.

A categoria "bruxa", bem como a prática de um determinado tipo de religiosidade definida pelas praticantes como bruxaria moderna, assenta-se em uma cosmovisão que dá à mulher um valor e um papel preponderantes no universo, não apenas dentro da prática ritualística, mas também na interpretação mitológica. Operase uma inversão valorativa, em que o pólo de maior valor é o feminino - o oposto do que ocorre em sociedades de dominação masculina (Bourdieu 2003). Os atributos femininos permanecem em grande medida os mesmos destas sociedades, mas o valor a eles atribuído não é negativo, e sim positivo. Na mesma lógica de inversão, ser bruxa não é uma acusação de malefício (Evans-Pritchard 1976), mas uma expressão de dons'. A categoria "bruxa" é uma auto-atribuição dos praticantes de wicca, que também se autodenominam wiccans, wiccanos ou wiccanianos.

Entre os dois gêneros, a mulher mantém-se como o sujeito preferencial da bruxaria, devido a uma visão de mundo que a relaciona à natureza, ao sobrenatural, à loucura e à magia. Toda mulher pode ser uma bruxa ou, em palavras de uma 
dom, visto como "natural" das mulheres, à custa de estudo, esforço e prática. Neste ambiente, a mulher tem a oportunidade de compor uma identidade de gênero pautada em atribuições tradicionais, ao mesmo tempo que modifica o valor dado a elas, segundo discursos feministas² subjacentes à prática wiccana.

\section{O QUE É A BRUXARIA MODERNA WICCA?}

A bruxaria wicca, segundo Grimassi ${ }^{3}$ (2000), é uma religião pagã herdeira das tradições e crenças das comunidades européias anteriores ao cristianismo. Alguns autores wiccanos traçam uma linhagem que viria diretamente da pré-história para os dias atuais, outros acreditam que a wicca foi formulada na Inglaterra na década de 1950. De qualquer forma, é possível perceber que a bruxaria wicca se propõe a ser uma releitura de práticas pagãs européias anteriores ao cristianismo, especialmente aquelas de origem céltica.

Em sua cosmologia, a wicca professa a crença em um par divino, chamados a Deusa e o Deus. A Deusa teria dado origem ao Deus e ambos teriam criado o universo e todas as coisas nele - ou seriam o próprio universo, a própria natureza. Sendo a primeira, Ela tem preeminência sobre o Deus, visto como seu filho e consorte, e essa preeminência se reflete nas práticas da wicca. Por isto, nos rituais, o lugar de destaque e liderança deve ser, tradicionalmente, de uma mulher.

Encarnando princípios da natureza, esse par se torna doador de vida. A Deusa é associada à terra, às águas e à lua. O Deus é associado ao sol e ao céu, algumas vezes aos animais e outras à vegetação. Eles representam princípios opostos, mas complementares. A Deusa, como terra, deve ser fertilizada por seu consorte, o Deus, que representa o sol. Ambos são divindades da natureza e operam segundo os ciclos naturais (solares). Os ritos das bruxas relativos ao percurso do sol durante o ano são chamados sabás. Mas como a lua representa igualmente a divindade feminina, toda lua cheia deve guardar também um rito próprio chamado esbá.

Vista pelas bruxas como sujeito mais próximo à natureza (Ortner 1979), a mulher guarda, na wicca, um local privilegiado para a atuação mágica. Há uma idéia difundida entre as bruxas wiccanas de que a mulher é o sujeito privilegiado da bruxaria. Outros praticantes de magia como feiticeiros, magos e xamãs são sempre referidos na forma masculina, enquanto as bruxas são referidas na forma feminina. Estes outros sujeitos são descritos pelas bruxas como simples operadores de magia, e não como membros de uma religião da natureza, como às vezes definem a wicca. Exceção deve ser feita ao xamã, que é visto como um ser ainda mais conectado à natureza do que as próprias bruxas, mas cuja atuação difere da delas. Nesse sentido, a bruxaria é freqüentemente descrita por seus praticantes como uma religião da terra, exatamente como o xamanismo, terra e natureza ganhando significados 
associados à divindade feminina.

Os instrumentos mágicos das bruxas, em grande parte, estão vinculados ao uso doméstico, espaço ainda hoje prioritariamente feminino. Caldeirões, facas, taças, vassouras, velas, sinos, espelhos, varinhas e espadas são os objetos mais comumente requeridos para rituais ou feitiços. Aqueles de forma longilínea, cilíndrica ou com corte são normalmente atribuídos à divindade masculina, e guardariam atributos masculinos. Aqueles de forma arredondada, ou usados como recipientes, são normalmente atribuídos à divindade feminina e portariam atributos femininos. Os papéis femininos são construídos de modo a formar uma oposição complementar aos masculinos. Para que haja equilíbrio, os dois devem estar presentes e devem atuar juntos.

Esta simbologia aponta para uma das características mais presentes na wicca no que se refere ao corpo, e que será vista adiante: a apropriação que se faz do útero na bruxaria moderna. Diz-se que o poder de uma bruxa reside em seu útero e que toda mulher nasce bruxa. O útero toma um lugar central para a wicca, pois é o lugar de criação do feminino, lugar onde uma outra vida é gerada. Ele guarda em si a possibilidade de transformação e renovação, que é a tônica da magia segundo a concepção da Nova Era. Mesmo a literatura específica de autoajuda, embebida de categorias psicológicas e psicanalíticas, trata exatamente da idéia de autotransformação e de mudança de si como um caminho para a mudança do mundo.

A wicca atribui ao masculino os papéis ativos, a guerra, a força, a luz, o selvagem. Ao feminino estão guardados os atributos da passividade, da fragilidade, da loucura, da escuridão e da cultura. $O$ último par é o que propõe que, na wicca, a valoração de gênero está construída de forma inversa àquela presente na nossa sociedade, colocando-se o feminino numa posição superior ao masculino. A civilização, a sofisticação da cultura, é apresentada como um atributo feminino, enquanto o masculino seria tosco, rude, selvagem. É fácil encontrar autores wiccanos e bruxas que acreditam que a bruxaria é proveniente de uma época da humanidade em que a sociedade se organizava em modelos matriarcais. Essa idéia corrobora a hipótese de que essa é uma religião centrada no feminino. $\mathrm{O}$ que é patente em todos os discursos elaborados pelas bruxas a respeito de sua própria história é que esta se constrói sempre em território europeu, está vinculada a um passado mítico ou distante, organiza-se pela procura do tradicional como um conceito legitimador e é centrada no feminino.

\section{PERFIS DAS BRUXAS RESIDENTES NA ÁREA DO RIO DE JANEIRO}

Para discutir as construções de gênero dentro do grupo estudado, foi realizada pesquisa de dois anos. Durante este período, levantei e analisei a literatura produzida pelas próprias bruxas. Também acompanhei listas de discussão 
na Internet, onde a sociabilidade do grupo se desenvolve em termos nacionais. Freqüentei reuniões de bruxas na cidade do Rio de Janeiro, bem como alguns rituais. Além disso, efetuei entrevistas com algumas bruxas.

A partir das oito entrevistas realizadas - uma delas com um homem, marido de uma das entrevistadas e também wiccano - pude construir um perfil das praticantes de wicca. São, em sua maioria, mulheres, entre vinte e cinco e cinqüenta anos. Na época em que as entrevistas forma realizadas (1999), três estavam solteiras. Das oito, quatro tinham dois filhos, e as outras quatro não tinham filhos. Apenas uma nunca tinha se casado. $\mathrm{O}$ grau de escolaridade variava entre o superior incompleto e o completo. A renda mensal familiar encontrava-se entre $R \$ 800,00$ e $R \$$ $6.000,00$, mantendo uma média de $\mathrm{R} \$ 1.500,00$ a $\mathrm{R} \$ 2.000,00$. Os bairros de habitação eram a Glória ${ }^{4}$, Tijuca, Lins ${ }^{5}$, Laranjeiras e Botafogo ${ }^{6}$, no Rio de Janeiro. Uma das bruxas mora em São Gonçalo, cidade de baixo poder aquisitivo próxima a Niterói. Esse perfil permite afirmar que as entrevistadas são, em sua maioria, de classe média baixa. Ao serem perguntadas sobre seu padrão de vida, apenas uma entrevistada não refutou a idéia de pertencer à classe média. As outras achavam que não mais pertenciam a esta classe, devido a problemas financeiros.

O perfil religioso de suas famílias fornece alguns dados relevantes. Todas as entrevistadas foram batizadas na Igreja Católica, seis cursaram o catecismo e cinco fizeram a Primeira Comunhão. Apesar de começarem a vida religiosa na Igreja Católica, elas mudaram de rumo posteriormente. Assim, duas afirmam ter freqüentado a Umbanda, o Kardecismo e o Budismo, num movimento claramente direcionado à religiosidade da classe média alta e da Nova Era. Uma das bruxas afirma ter freqüentado a Igreja Messiânica. As outras cinco travaram outras buscas espirituais, passando pelo Kardecismo ou a Umbanda e desaguando no conhecimento Nova Era, até chegarem à wicca.

Após os caminhos religiosos expostos, essas pessoas optaram por uma expressão religiosa importada da Europa e dos Estados Unidos, de onde provém a maioria dos autores sobre wicca. Como foi visto, a bruxaria que praticam é a européia. Márcia Frazão, primeira bruxa brasileira a escrever livros sobre bruxaria européia no país, é sempre criticada por seus pontos de vista, que insistem em defender a idéia de uma bruxa do povo, isto é, uma bruxaria com raízes nas rezadeiras e benzedeiras brasileiras. Essa proximidade com o Brasil é incômoda para estas bruxas, que buscam sistemas de crenças provenientes de países estrangeiros e sem paralelo aparente na cultura brasileira. A benzedeira faz parte da cultura mágica popular do país, mas ela não é uma bruxa. Ela é uma curandeira (Maluf 1993).

Por outro lado, para muitas das entrevistadas, a bruxaria e o meio esotérico se tornaram profissão, provendo seu sustento. Das entrevistadas, quatro trabalhavam exclusivamente nesse mercado, e duas esporadicamente, como uma extensão de seus trabalhos. Desempenhavam o papel de videntes (taróloga, runóloga, astróloga, cartomante) ou ocultistas (numeróloga, radiestesista) ${ }^{7}$, sendo palestrantes em feiras e eventos esotéricos, dançarinas e comerciantes. Uma delas oferece um curso de bruxaria wicca, no qual é possível aprender todo o conhecimento 
das bruxas wiccanas e praticar seus feitiços e rituais. Existem vários outros cursos de bruxaria no país, em cidades como São Paulo e Brasília. Percebe-se, portanto, que a identidade de bruxa não é apenas uma identidade de gênero, mas uma persona completa, que vive a bruxaria como profissão e religião, e que está amparada na busca de um status de classe e de gênero.

Por ser um universo tão vinculado ao feminino, foi possível observar, no campo, um fenômeno análogo àquele que ocorre nos terreiros de Candomblé (Birman 1995), que é a predominância de homens homossexuais. De fato, não foi possível averiguar se esta predominância é factual ou imaginada, embora haja homossexuais masculinos e femininos praticantes de wicca: diversas vezes ouvi comentários sobre a orientação sexual de praticantes da wicca, não apenas do Rio de Janeiro, mas também daqueles mais conhecidos no universo wiccano, residentes em Brasília ou São Paulo. Percebi que as bruxas sempre falavam sobre o homossexualismo masculino na wicca, e se referiam à maioria dos homens como sendo homossexuais.

Para entender por que a homossexualidade masculina tornou-se uma questão dentro do próprio universo wiccano, é necessário apontar para três fatores: primeiro, a faixa etária dos praticantes masculinos, quase todos abaixo dos trinta anos; segundo, a idéia de que os homossexuais têm maneiras femininas; terceiro, as vantagens que um homossexual masculino pode ter praticando wicca.

A primeira impressão, no campo, é que as mulheres que praticam wicca são de todas as faixas etárias, começando a se interessar por bruxaria aos treze ou catorze anos e estendendo-se até aos cinqüenta. Os homens, por outro lado, são todos jovens. É difícil encontrar um wiccano com mais de trinta anos. O reflexo das mudanças quanto aos papéis de gênero na nossa sociedade parece fundamental para se compreender o fenômeno, tanto quanto a estrutura de gêneros que a wicca apresenta. Apesar do ingresso de homens na bruxaria, esta ainda tem sido um espaço feminino onde a predominância numérica das mulheres é sensível.

A wicca é uma prática que não apresenta concepções hierárquicas sobre os gêneros, especialmente no sentido da dominação masculina, embora tenda a formular o feminino como gênero preeminente em suas práticas e doutrina. Os homens que praticam a wicca ficam, deste modo, numa posição que não podem manter um comportamento considerado machista no sentido da dominação masculina anterior ao feminismo. Uma mulher que acredita que toda mulher nasce bruxa, ou que o poder de uma bruxa reside em seu útero, exclui dos homens a capacidade inata para a bruxaria que a mulher teria e torna-o um sujeito menos apto a tal prática, dominando este espaço e legitimando esta dominação. Os homens que acompanharem as bruxas wiccanas, portanto, terão que ser homens pós-revolução feminista. No Brasil, a mudança no status da mulher na sociedade só se deu a partir da década de 1970, e mais fortemente da década de 1980 (Goldani 1993; Oliveira 1996; Berquó 1998). Não seria possível, portanto, que uma grande quantidade de homens com mais de trinta anos pudesse comungar das 
crenças wiccanas. De fato, a partir de observações de campo na cidade do Rio de Janeiro e de perfis coletados durante a pesquisa em listas de discussão na Internet, pude perceber que o público masculino interessado em wicca estava fundamentalmente abaixo dos trinta anos.

Se, por um lado, o pensamento e a prática wiccanas impediam comportamentos machistas da parte deles, impedindo uma apresentação do masculino baseado na força e na dominação, por outro, o homossexualismo masculino continuou sendo relacionado ao feminino. Uma das bruxas entrevistadas, referindo-se à suas constantes suspeitas sobre a orientação sexual dos bruxos, disse que "são todos muito femininos". Dada a construção de gêneros na wicca, as representações das bruxas sobre o masculino ficaram encerradas em uma espécie de dilema: os homens não podem apresentar um comportamento segundo os padrões da dominação masculina (Bourdieu 2003), mas se não o apresentam são vistos como femininos e suspeita-se que sejam homossexuais, ou bissexuais, caso o grau de amizade permita conhecer suas parceiras sexuais. Forma-se, então, um imaginário que correlaciona os praticantes masculinos de wicca à prática homossexual, embora eu tenha conhecido wiccanos no Rio de Janeiro sobre quem suspeitas de homossexualismo jamais recaíram.

Mas como uma religião centrada no poder do feminino poderia comportar tantos homossexuais? De fato, os homossexuais encontram na wicca um espaço de feminilidade relativamente parecido com aquele que paisde-santo encontram no Candomblé. Embora na literatura wiccana estrangeira seja possível encontrar algumas referências à presença de lésbicas na bruxaria, o mesmo não se dá a respeito dos gays. Lésbicas, embora sejam homossexuais, permanecem dentro da categoria mulher, o que significa que o poder da bruxa é intrínseco à mulher, não importando qual a expressão de sua sexualidade. Ele é inerente e por isso não exclui as lésbicas. Os homossexuais masculinos, contudo, só se fazem inserir no sistema wiccano através de um artifício de gênero.

Viu-se que o princípio masculino é definido na wicca em relação à sua sexualidade: ele é fertilizador e só poderá sê-lo se estiver numa relação com o princípio feminino. Um gay não apresenta esses atributos masculinos. Ele é levado, então, a tentar incorporar os atributos femininos. Utilizando as categorias de Fry (1982), entenderemos que homem está em oposição a mulher, enquanto bicha ou entendido (homossexual) estão em oposição a homem (heterossexual). Ou seja, o homossexualismo masculino joga o sujeito na categoria "mulher", tornando-o um ser feminino. Deste modo, o homossexual masculino na wicca se torna mais próximo às mulheres e tende a buscar, tanto quanto elas, um espaço de identidade de gênero e de atuação profissional. Isto não quer dizer que todos os homens bruxos sejam gays. Na verdade, poucos assumem a condição homossexual, que é comentada em sussurros por meio de fofoca, sempre mais como suspeita do que como fato publicamente conhecido. 


\section{IDENTIDADE FEMININA E IDENTIDADE DE BRUXA}

Para desenvolver a análise sobre a identidade de bruxa, farei uso de modelos analíticos que fazem distinção entre sociedades tradicionais e modernas, explicitando as diferentes identidades femininas em cada modelo. Tento, com isto, determinar em qual modelo as bruxas estudadas estão inseridas, ou, em outras palavras, qual modelo de mulher tomam para si. Uma vez que a prática da bruxaria é normalmente associada a sociedades tradicionais, este se torna um ponto relevante.

O papel da mulher na sociedade brasileira tradicional, organizada a partir da família hierárquica, extensa e patriarcal, era definido no casamento. Como apontada por Durham (1983), a divisão sexual do trabalho reservava à mulher os cuidados da esfera privada da vida, a esfera doméstica e o cuidado com as crianças. A mulher da sociedade tradicional tinha sua própria identidade definida nessa hierarquia: inferior ao homem, seu comportamento, sentimentos, vestimentas e linguagem eram definidos dentro desse rígido esquema hierárquico (Figueira 1987). Lipovestky (2000) afirma que nas sociedades pré-modernas, mesmo consagrada às tarefas domésticas, a mulher não se dedicava exclusivamente a estas. Seu trabalho era fundamental para a economia familiar, seja ela baseada na agricultura ou algum tipo de manufatura. A esposa-mãe-dona-de-casa é, para este autor, uma idealização.

A mudança desse tipo de sociedade para uma sociedade mais igualitária, moderna, abre a possibilidade de a mulher construir uma identidade de sujeito definida a partir do gosto pessoal, e não mais dada por uma hierarquia social. Embora o processo de modernização no país esteja ainda incompleto, ele abre a possibilidade de que a mulher encontre novas identidades que não a definam exclusivamente pela sua atuação na esfera doméstica (Figueira 1987). É a mudança na autonomia feminina, em grande parte fruto do crescimento do nível de escolaridade das mulheres e sua entrada no mercado de trabalho, que tem proporcionado a mudança nos arranjos familiares brasileiros. Essa mudança proporciona também a possibilidade de que a identidade feminina seja agora construída não mais exclusivamente na família e no casamento, mas também na esfera pública, no mercado de trabalho (Goldani 1993; Oliveira 1996; Berquó 1998).

Lipovetsky (2000), escrevendo sobre a mulher, utiliza não apenas a oposição entre tradicional e moderno, mas acrescenta a idéia de uma mulher pós-moderna. Na modernidade, segundo o autor, o ideal tradicional da "boa esposa e mãe" não desaparece, mas a retórica de sacrifício que o acompanhava encontra-se mascarada por normas individualistas. Hoje, segundo ele, a nova condição da mulher se caracteriza por uma recusa em construir uma identidade baseada nas funções de mãe e de esposa. A atividade profissional das mulheres se tornou um valor e uma aspiração. Para o autor, este foi um processo no qual as mulheres tiveram suas habilidades tradicionais cada vez mais desqualificadas em nome de uma nova ordem científica e médica. Esta tentativa de "aculturação" do saber feminino foi acompanhada da reclusão da mulher à esfera doméstica exclusivamente. 
Para o autor, o ingresso da mulher em atividades profissionais leva à adoção de atitudes que significam a busca por um sentido para a vida pessoal e expressam um desejo de ser sujeito da própria existência. Para o autor, a cultura do trabalho propicia às mulheres a conquista de uma identidade profissional plena e indica um desejo, por parte delas, de serem reconhecidas a partir do que fazem e não do que são "por natureza", como mulheres. Segundo este autor, o que domina no perfil da mulher pós-moderna (não entrarei aqui na discussão sobre a modernidade e a pós-modernidade) é o investimento feminino na vida profissional e a rejeição a uma identidade baseada exclusivamente nos papéis domésticos.

Muchembled (1987) é outro autor que afirma que a modernidade retirou das mulheres saberes que lhes eram tradicionais. No caso da bruxaria wicca, pode-se notar que as bruxas de hoje retomam, em alguma medida, este mesmo discurso para resgatar seu papel tradicional e seus saberes tradicionais, hoje não mais contra a ordem científica vigente, mas contra o domínio masculino e o patriarcado. Segundo Lipovetsky (2000), a única função que escapa à desvalorização sistemática da mulher é a maternidade. Interessante notar como esse ponto é fundamental na bruxaria wicca, onde o tema é trabalhado à exaustão, tanto nos rituais e mitologia quanto na própria aproximação com a divindade.

A partir destas categorias, a saber, tradicional, moderno e pós-moderno, como classificar a identidade de bruxa referente à wicca? Parte dos dados parece apontar para uma forte utilização de concepções tradicionais sobre o feminino, enquanto parte deles aponta para a emergência de uma postura moderna entre as bruxas estudadas.

A construção de uma relação hierarquizada entre homens e mulheres - apesar de sua inversão valorativa -, com uma valorização dos saberes tradicionais femininos, demonstra uma forte presença de concepções tradicionais na wicca. Por outro lado, a inversão valorativa dos gêneros e a entrada da mulher no mercado de trabalho são aspectos que indicam a emergência de concepções modernas. $O$ trabalho, o casamento e a maternidade são, segundo Lipovetsky (2000), características da mulher moderna. Apenas a mulher pós-moderna teria rompido com as aspirações do casamento e da maternidade como elementos formadores de uma identidade feminina.

A conversão a uma religião onde o feminino é valorado positivamente em detrimento do masculino só é possível numa sociedade moderna ou a caminho da modernidade (Figueira 1987; Giddens 1991; Lipovestky 2000). Mas, ao perguntar o que essas mulheres buscam na bruxaria, deparei-me com relatos construídos de modo a fazer com que a bruxaria se tornasse um destino quase inescapável e não uma escolha, quando na modernidade não há destino, mas escolhas, tornando a categoria bruxa uma construção identitária, uma vez que o discurso das entrevistadas aponta para a idéia de que elas são bruxas "desde sempre", ou por terem nascido bruxas ou porque toda mulher o é.

A partir do material de campo, percebe-se que a identidade de bruxa não constitui apenas uma identidade de gênero com recurso ao tradicional. Para as bruxas entrevistadas, pode-se tornar uma profissão. No caso das bruxas, 
há todo um discurso no sentido de mostrar que toda mulher é uma bruxa, ou que a bruxa o é desde o nascimento. Nesse caso, o que ela faz - a profissão de bruxa - é pensado como uma expressão de quem ela é: uma bruxa e, em última instância, uma mulher. Assim, as bruxas entrevistadas se apresentam como fruto da modernidade tanto em sua busca por uma identidade profissional quanto em sua busca por saberes tradicionalmente femininos (perdidos na própria modernidade), de modo a romperem com uma identidade construída apenas a partir do binômio mãe-esposa e também em relação ao homem quando numa posição de subordinação.

Das sete bruxas e um bruxo entrevistados, seis se inserem direta ou indiretamente no mercado esotérico como profissionais. Desses, apenas dois não trabalham diretamente com os conhecimentos que uma bruxa possui, no sentido de transformar a bruxaria em profissão. Quando uma das entrevistadas manifesta interesse em ingressar também no mercado esotérico, percebe-se que esse é um desejo movido pela necessidade de adequar o trabalho remunerado com a identidade de bruxa e não somente pela dificuldade de entrada em outros ramos do mercado de trabalho. Este desejo fica mais claro quando se observa que a entrevistada em questão tem um emprego estável (funcionária pública) e futuramente acredita que terá qualificação (estuda Direito) para conseguir ganhos mais altos que os atuais. É o gosto pessoal, característica da modernidade, que opera aqui.

Embora uma das entrevistadas tenha relatado sua entrada no mercado esotérico como fruto do desespero financeiro, não vejo essas duas posições como opostas. Na verdade, o fato de serem bruxas, além de possuírem qualificação formal (nível superior), possibilitou a essas mulheres a perspectiva de ingresso em mais de um ramo de atividade profissional. A permanência no ramo esotérico se deve a uma escolha deliberada por parte delas. Essa visão é corroborada pelo desejo de ingresso nesse mercado por quem está fora dele, mesmo sem problemas financeiros e com grandes chances de sucesso profissional, dada sua qualificação.

Através dessas entrevistas, nota-se também que a maior parte das bruxas é ou foi casada, o casamento entendido aqui também como coabitação (união consensual). Das sete mulheres entrevistadas, seis são ou já foram casadas. Destas, quatro têm filhos. Estes dados indicam que a identidade de bruxa não impossibilita essas mulheres para o matrimônio. Mas estes dados apontam também para um outro lado: através da bibliografia produzida pelas bruxas, percebe-se que toda a esfera de atuação da bruxaria é feminina e doméstica. Os instrumentos mágicos como o caldeirão, a vassoura, o punhal e a taça deixam isto claro, bem como a idéia de manter uma horta de ervas mágicas, realizar feitiços na cozinha ou enquanto se faz trabalhos domésticos, ou na idéia de que o útero é o lugar de força e poder de uma bruxa, sendo o sangue menstrual considerado magicamente poderoso.

Neste ponto, cabe um questionamento sobre o quanto a identidade de bruxa rompe com valores tradicionais e expressa a "modernização" da mulher e o quanto essa identidade, na verdade, ajuda a reconstruir para a mulher moderna papéis tradicionais de gênero. Em ambos os casos, na verdade, está-se diante de expressões de modernidade. 
De fato, não parece ser o caso de uma volta aos papéis tradicionais, mas de uma valorização de atributos tradicionais das mulheres, estando o feminino compreendido ainda em termos tradicionais, mas não valorado segundo eles.

Quando se tomam as classes médias, das quais as entrevistadas fazem parte, como modernizadas ou em um processo de modernização (Figueira 1987), então é possível enxergar a identidade de bruxa tanto como fruto dessa modernização quanto como um recurso à tradição. Neste último caso, trabalho com a idéia de que essas classes são modernizadas, causando em seus sujeitos o que Giddens (1991) chama de desencaixe. O desencaixe é uma conseqüência da modernidade, cujo rompimento com sistemas tradicionais faz com que os sujeitos percam referenciais. A identidade do sujeito moderno é um dado em aberto e é de sua própria responsabilidade. Através de sua reflexividade, ele escolhe que tipo de pessoa deseja ser, que tipo de vida deseja levar, para onde quer ir, que profissão ter.

A construção da identidade, no entanto, demanda uma certa estabilidade, que pode ser buscada no recurso à tradição ou à religião, por exemplo. Este recurso à estabilidade é uma resposta aos mecanismos de desencaixe. Como sujeitos desencaixados, as bruxas podem recorrer ao tradicional para a reformulação de uma nova identidade que mantenha os ganhos da modernidade para as mulheres (independência financeira, escolhas individuais, por exemplo) ao mesmo tempo que estabelece atividades de gênero em parte tradicionais para elas. Não há, sob este ponto de vista, um retorno à tradição, mas uma utilização moderna desta. O re-encaixe alcançado pela religião, no caso estudado, fornece uma valorização de uma maneira de ser que talvez não fosse valorizada em outros contextos.

A religião hoje é uma escolha do sujeito. Pode ser um meio de preservar uma determinada identidade sob risco na modernidade, ou de construir uma. No primeiro caso, que acredito ser o da bruxaria wicca, a identidade é mantida através da recuperação de doutrinas, crenças e práticas de um passado considerado sagrado. Essas doutrinas, crenças e práticas são modificadas e sofrem inovações, dando ensejo a um perfil religioso novo. A religião passa a servir de re-encaixe, tradicional apenas na aparência, porém moderna e atual. É um discurso de retorno à tradição que inova e se direciona para a modernidade.

A bruxaria wicca não rompe com a tradicional atribuição de funções aos gêneros, nem com a tradicional divisão sexual do trabalho. O que ela traz de inovador é a inversão da valoração usual para os gêneros. Na wicca, o feminino é mais valorizado pela sua capacidade de criação, e por uma série de atributos tidos como naturais nas mulheres: sensibilidade, generosidade, beleza, sutileza, calma, intuição, imaginação, criatividade, entre outros. O masculino, por sua vez, seria eminentemente agressivo, belicista, forte, racional, entre outros atributos. Essas atribuições não são modernas, mas tradicionais. A inovação da bruxaria wicca é a visão de que exatamente por ser o que é, o feminino é positivamente valorado, o que não ocorre nas sociedades tradicionais. 
inclusive no mercado de trabalho, ao mesmo tempo que pode vir a reforçar padrões tradicionais de divisão sexual do trabalho, sem romper de todo com o modelo de família brasileira (casal com filhos). Neste caso, exatamente como a sociedade brasileira, a filosofia expressa pela bruxaria wicca parece exercer regras de "modernização reativa" (Figueira 1987), pois mantém o padrão em que um dos sexos é valorizado em detrimento do outro, mas muda o sexo em questão do homem para a mulher. Fica, portanto, uma indicação de como a wicca tem sido professada no país e do porquê ela ter atingido estratos urbanos quando sua proposta de "comunhão com a natureza" apontaria para um caminho mais rural.

Quanto ao aparente reforço que a bruxaria traz aos padrões tradicionais, é interessante aqui retomar a discussão que Lipovestky (2000) faz sobre a mulher contemporânea. Para este autor, existem três tipos de mulher: a "primeira mulher" é aquela diabolizada, associada ao caos e ao mal, que lida com magia; a "segunda mulher" é aquela idealizada a partir da Idade Média, vista como mais próxima da divindade do que o homem, é a mãe enaltecida, a força civilizadora; a "terceira mulher" seria a mulher que rompe com essas idealizações e abole a hierarquia social dos sexos, apresentando uma autonomização do seu ser (característica das democracias ocidentais), embora as desigualdades entre os sexos não desapareçam de todo.

A identidade de bruxa bebe, claramente, em todas essas fontes. A princípio mais próxima da "primeira mulher" por sua íntima relação com a magia e pela visão folclórica da bruxa como um ser ligado ao mal, pode-se perceber no discurso atual das bruxas uma certa influência da "segunda mulher", tanto na adoração da face de Mãe que sua divindade apresenta, como na idéia da mulher enquanto força civilizadora e ser mais próximo da divindade - no caso das bruxas, pela relação óbvia entre uma divindade feminina prevalecente e a mulher. A partir dessas influências, a bruxa contemporânea parece emergir como uma identidade nova, absorvendo as conquistas da "terceira mulher". Para as próprias bruxas, contudo, sua identidade é vista muito mais como tradicional do que moderna, uma vez que acreditam que sua religião foi reformulada a partir da religião praticada no período matriarcal da humanidade e uma vez que procuram pelos saberes tradicionais femininos.

\section{CONSIDERAÇÕES FINAIS}

A mulher é sujeito privilegiado da bruxaria. O que faz dela bruxa é a sua posição desviante numa ordem dada: ela é associada à natureza; ela é tornada marginal como sujeito subordinado na ordem da dominação masculina; ela retém atributos que a diferenciam do ideal dominante, que é masculino. Nas últimas décadas, a mulher tem conseguido rever alguns aspectos de seu status social frente ao patriarcado. Com todos os ganhos de hoje, 
porque ela estaria disposta a retomar uma identidade vinculada à marginalidade e a atribuições tradicionais de gênero? Mas será que é isto que as bruxas modernas têm de fato buscado, quando decidiram, em primeiro lugar, tornarem-se bruxas?

Se o espaço da mulher não é ainda de plena igualdade com os homens, não é também possível dizer que nada mudou. O papel da mulher dentro da economia doméstica, apesar de tudo, foi o que sofreu a menor mudança. Embora ela seja hoje, muitas vezes, a única provedora do lar, ou pelo menos uma contribuinte importante, na maior parte das vezes o trabalho doméstico ainda é tarefa sua.

A bruxaria parece, como afirma Del Priore (1997), ser uma inversão do pejorativo feminino numa afirmação de suas qualidades enquanto mulher. Se para os homens a menstruação continua parecendo algo impuro, na bruxaria ela é divina e repleta de poder. Se a atividade da mulher como dona-de-casa ainda é vivenciada por muitas como uma submissão, na bruxaria ela é percebida como um espaço de liberdade para plantar ervas para feitiços, proteger a casa de influências nefastas, tomar conta da cozinha onde se utilizam vários instrumentos mágicos e realizar feitiços com o caldeirão, a taça, o athame (punhal), a varinha, a vassoura, entre outros.

Em suma, o que sugiro é que, dadas as mudanças na condição feminina, o que se viu nos últimos anos foi a perda, por parte da mulher, exatamente daquilo que fazia dela mulher. Ela continua a parir filhos, cuidar deles, da casa, da família, mas, ao entrar no mercado de trabalho, ela sofre uma transformação na tentativa de se manter competitiva e alcançar outros postos. As mulheres que trabalham fora não raras vezes deixam a casa nas mãos de uma empregada doméstica e os filhos nas mãos de uma babá ou parente. Em parte, elas perderam aquela ligação com o que era antes o mundo feminino, e perderam também aquela cultura feminina que o processo de modernização Ihes roubou (Muchembled 1987). Assim, a bruxaria parece um caminho aberto para algumas mulheres recuperarem uma identidade feminina, uma cultura e um mundo feminino perdidos. Claro que essa recuperação não é a de uma velha rotina. As bruxas modernas trabalham, casam e têm filhos. Elas são mulheres do mundo contemporâneo, mas parecem buscar na bruxaria um pouco daquela velha condição feminina que lhes foi de certa forma roubada.

As bruxas entendem que a wicca é uma religião orientada para o feminino. Afirmam que a evocação da divindade feminina orienta a wicca para o feminino e vão além: para algumas, toda mulher é bruxa, isto é, "tem útero, é bruxa". Essa afirmação desvenda o papel do útero na formulação do poder mágico dentro da bruxaria. É o poder de procriação, de gerar vida, que o útero traz implícito, e por isso ele se torna tão importante. Ele é um gerador de energia. É ele que faz a mulher ser mulher e faz da mulher uma bruxa, pois é um poder feminino.

No período inquisitorial, considerava-se que a bruxaria era um mal hereditário. Hoje a idéia persiste, mas a bruxaria, de mal, tornou-se um dom. Frazão (1995) afirma ser uma bruxa hereditária, que teria aprendido sua 
arte com suas avós e tias, também bruxas. Entre as bruxas brasileiras, é comum afirmarem que há outras bruxas na família, normalmente definidas pelo dom. Neste caso, costumam se referir a familiares mulheres mais do que a homens, o que parece reforçar a idéia de que a bruxaria é um esforço do feminino no sentido de organizar uma nova identidade. Formular uma história familiar que corrobore o sentido dessa identidade é fundamental, é um recurso de legitimidade da condição de bruxa.

De acordo com as bruxas pesquisadas, a wicca é um caminho tanto de busca quanto de transformação. Essa transformação é interna, uma mudança "em todos os níveis" que viria através da magia, dos rituais, das práticas religiosas. Para as entrevistadas, a bruxaria modifica o seu praticante, sua maneira de ver o mundo ou o seu próprio Eu. Em outras palavras, poderíamos dizer que ela modifica a identidade pessoal subjetiva de seu praticante, sua percepção de si e do mundo.

Em um período marcado pelo predomínio da razão, como o que vivemos, uma prática mágica antiga é resgatada por um grupo de mulheres (e homens), de forma que a antiga ligação estabelecida entre bruxaria e universo feminino retorna e a ligação entre a mulher e a natureza é destacada, de modo não a sofrer uma crítica, mas uma reafirmação. Esta situação formula, a meu ver, a intenção de construir um novo papel para a mulher na sociedade contemporânea, ou a intenção de marcar este novo papel. 


\section{NOTAS}

1 Os dons em questão seguem duas linhas distintas: por um lado, o discurso das bruxas pesquisadas opera com categorias da Nova Era, sobretudo na idéia de paranormalidade; por outro, há um discurso que toma categorias do espiritismo, como mediunidade.

2 Há correntes de prática wiccana que são essencialmente feministas, inclusive algumas que só aceitam mulheres.

3 Grimassi é wiccano.

4 Glória é um bairro próximo ao centro da cidade, pouco valorizado, embora considerado como Zona Sul. A cidade do Rio de Janeiro está dividida em quatro zonas espaciais (Zonas Sul, Norte, Oeste e Centro), que correspondem a perfis sócio-econômicos. A Zona Sul é a área mais valorizada, onde o poder aquisitivo é maior. As Zonas Norte e Oeste são menos valorizadas, com poder aquisitivo menor, incluindo-se nestas o que se chama geralmente por subúrbio. Na Zona Oeste destaca-se a Barra da Tijuca, local onde certas famílias ricas, chamadas emergentes, se estabeleceram. O diferencial dos emergentes é a riqueza alcançada por meio do trabalho, em comparação com fortunas herdadas de família. O Centro é a região financeira e de negócios, habitada em alguns bairros por uma população de pouco poder aquisitivo.

5 Tijuca e Lins são bairros da Zona Norte.

6 Laranjeiras e Botafogo são bairros da Zona Sul menos valorizados, com menor poder aquisitivo.

7 Tarólogo é aquele que joga o baralho de tarot na forma de oráculo. Runólogo é aquele que consulta as runas (pedaços de madeira, pedra ou osso com símbolos de origem nórdica entalhados) como oráculo. Radiestesista é aquele que utiliza o pêndulo como forma de medir as energias e emanações de um determinado lugar. Astrólogo é conhecedor de astrologia. Numerólogo é aquele que domina a ciência oculta dos números. 


\section{REFERÊNCIAS BIBLIOGRÁFICAS}

BERQUÓ, Elza. 1998. "Arranjos Familiares no Brasil: uma visão demográfica". In Fernando A. Novais \& Lilia Moritz Schwarcz (orgs.) História da Vida Privada no Brasil 4. São Paulo: Cia. das Letras.

BIRMAN, Patrícia. 1995. Fazer Estilo Criando Gêneros. Rio de Janeiro: Eduerj \& Relume-Dumará.

BOURDIEU, Pierre. 2003. A Dominação Masculina. Rio de Janeiro: Bertrand Brasil.

DEL PRIORE, Mary. 1997. “Magia e Medicina na Colônia: o corpo feminino". In no Brasil. São Paulo: Contexto.

(org.) História das Mulheres

DURHAM, Eunice. 1983. “Família e Reprodução Humana”. In Bruna Franchetto; Maria Laura V. C Cavalcanti; Maria Luisa Heilborn, (orgs.) Perspectivas Antropológicas da Mulher 3. Rio de Janeiro: Zahar.

EVANS-PRITCHARD, E. E. 1976. Bruxaria, Oráculos e Magia entre os Azande. Rio de Janeiro: Zahar.

FIGUEIRA, Sérvulo A. 1987. “O Moderno e o Arcaico na Nova Família Brasileira: notas sobre a dimensão invisível da mudança social". In Brasileira. Rio de Janeiro: Jorge Zahar.

FRAZÃO, Márcia. 1995. Manual Mágico do Amor. Rio de Janeiro: Francisco Alves.

FRY, Peter. 1982. Para Inglês Ver. Rio de Janeiro: Zahar.

GIDDENS, Anthony. 1991. As Conseqüências da Modernidade. São Paulo: Unesp.

GOLDANI, Ana Maria. 1993. "As Famílias no Brasil Contemporâneo e o Mito da Desestruturação". Cadernos Pagu $1: 67-110$.

. 1994. "Retratos de Família em Tempos de Crise". Estudos Feministas. n. especial/ $2^{\circ}$ sem : 303-335.

GRIMASSI, Raven. 2000. Os Mistérios Wiccanos: antigas origens e ensinamentos. São Paulo: Gaia.

LIPOVESTKY, Gilles. 2000. A Terceira Mulher: permanência e revolução do feminismo. São Paulo: Cia. das Letras.

MALUF, Sônia. 1993. Encontros Noturnos: bruxas e bruxarias na Lagoa da Conceição. Rio de Janeiro: Rosa dos Tempos.

MUCHEMBLED, Robert. 1987. Sorcières: justice e société aux XVI e XVII siècles. Paris: Imago.

OLIVEIRA, Maria Coleta. 1996. “A Família Brasileira no Limiar do ano 2000". Estudos Feministas 1(4): 55-63.

ORTNER, Sherry. 1979. "Está a Mulher para o Homem Assim como a Natureza para a Cultura?" In Michelle Zimbalist Rosaldo \& Louise Lamphere. A Mulher, a Cultura, a Sociedade. Rio de Janeiro: Paz e Terra. 


\section{Bruxas Modernas: um estudo sobre identidade feminina entre praticantes de wicca}

\section{RESUMO}

Entre 1999 e 2000, estudou-se um grupo de bruxas praticantes de wicca. Este grupo é formado por uma maioria de mulheres, que se designam como bruxas. Operam dentro da idéia de uma bruxaria moderna que retoma características da bruxaria tradicional, mas sem a idéia de acusação ou malefício. A wicca utiliza concepções tradicionais sobre os gêneros, invertendo a valoração costumeiramente encontrada para ambos, dando ao feminino maior valor, o que se traduz na preeminência das mulheres em sua teologia e práticas rituais. A pesquisa de campo permitiu estabelecer um perfil para praticantes de wicca na área do Rio de Janeiro.

PALAVRAS-CHAVE: identidade feminina, bruxaria, wicca.

\section{Modern Witches: a study of feminine identity among wicca practitioners}

\section{ABSTRACT}

A group of witches practitioners of wicca has been studied between 1999 and 2000. This group is composed mostly by women who designate themselves as witches. They operate with a notion of modern witchcraft that appropriates some characteristics of traditional witchcraft, but not the idea of accusation or misdeed. The wicca also uses traditional gender conceptions, inverting the valuation of both genders usually found, giving the feminine a higher value, which is translated in the preeminence of women in its theology and ritual practices. Field research allowed the establishment of the profile of wicca practitioners in the Rio de Janeiro area.

KEY WORDS: feminine identity, witchcraft, wicca. 